\title{
Linoleic acid-rich fats reduce atherosclerosis development beyond its oxidative and inflammatory stress-increasing effect in apolipoprotein E-deficient mice in comparison with saturated fatty acid-rich fats
}

\author{
Masao Sato, Kenichi Shibata, Run Nomura, Daisuke Kawamoto, Rika Nagamine and Katsumi Imaizumi* \\ Laboratory of Nutrition Chemistry, Division of Bioresource and Bioenvironmental Sciences, Graduate School, Kyushu University, \\ Fukuoka 812-8581, Japan
}

(Received 16 September 2004 - Accepted 7 January 2005)

\begin{abstract}
The relative benefit of replacing saturated fatty acid with linoleic acids is still being debated because a linoleic acid-enriched diet increases oxidative and inflammatory stresses, although it is associated with a reduction in serum cholesterol levels. The present study was conducted to evaluate the effect of dietary supplementation of linoleic acid-rich (HL) fat, compared with a saturated fatty acid-rich (SF) fat on atherosclerotic lesion areas, serum and liver cholesterol levels, oxidative stress (urinary isoprostanes and serum malondialdehayde) and inflammatory stress (expression of aortic monocyte chemoattractant protein1; MCP-1) in apo E-deficient mice. Male and female apo E-deficient mice (8 weeks old; seven to eight per group) were fed an AIN-76-based diet containing $\mathrm{SF}$ fat $(50 \mathrm{~g}$ palm oil and $50 \mathrm{~g}$ lard $/ \mathrm{kg})$ or HL fat $(100 \mathrm{~g}$ high-linoleic safflower-seed oil $/ \mathrm{kg})$ for 9 weeks. Compared with the SF diet, the HL diet lowered atherosclerosis $(P<0 \cdot 05)$. It reduced serum total cholesterol levels $(P<0 \cdot 05)$, increased HDL-cholesterol levels $(P<0 \cdot 05)$ and lowered liver esterified cholesterol levels $(P<0 \cdot 01)$. The HL diet-fed mice showed increased expression of MCP-1 mRNA $(P<0 \cdot 05)$, serum levels of malondialdehayde $(P<0.05)$ and urinary excretion of 2,3 -dinor-5,6-dihydro-8-iso-prostaglandin $\mathrm{F} 2 \alpha ; P<0.05)$. These results suggest that having biomarkers in vivo for oxidative stress and inflammatory status of endothelial cells does not necessarily indicate predisposition to an increased lesion area in the aortic root in apo E-deficient mice fed an HL or SF diet.
\end{abstract}

Apolipoprotein E-deficient mice: Linoleic acid: Monocyte chemoattractant protein-1: Saturated fatty acids

Endothelial dysfunction is a key variable of atherosclerosis where elevated serum cholesterol levels are associated with endothelial dysfunction (Vogel, 1999). Endothelial dysfunction is also associated with increased oxidative stress, an important promoter of inflammatory processes (Napoli et al. 2001). In man, saturated fatty acids increase the levels of LDL- and VLDL-cholesterol, and current recommendations include decreasing their intake as part of a heart-healthy diet (Krause et al. 2000). Non-human primate studies have shown that consuming a saturated fatty acidrich (SF) diet compared with a linoleic acid-rich (HL) diet results in increased serum levels of LDL-cholesterol (Rudel et al. 1995). In contrast, observations from in vitro studies show that increased intake of linoleic acid leads to increased oxidative stress, which may be associated with endothelial dysfunction (Mertens \& Holvoet, 2001; Moreno \& Mitjavila, 2003). However, compelling evidence that this occurs in vivo is still lacking, although Turpeinen et al. (1998) showed that urinary excretion of 8-iso-prostaglandin $F 2 \alpha$ (8-iso-PGF2 $\alpha)$, which increases in situations associated with oxidative stress (Morrow et al. 1995), is increased after consumption of an HL diet by healthy subjects. Thus, the status of endothelial function after consumption of these fatty acids can be regarded as an integrated index of all atherogenic and atheroprotective factors in a given individual, because cardiovascular risk factors such as hyperlipidaemia, hypertension, diabetes and smoking, local factors including shear stress, genetic factors, and unknown factors determine the status of endothelial function (for a review, see Bonetti et al. 2003).

The advantage of using animal models to examine the effect of dietary fats is that the level of serum cholesterol, the in vivo status of oxidative or inflammatory stresses and atherosclerosis can simultaneously be determined at the end of the study. Thus, we conducted the present study to investigate the effects of dietary enrichment of linoleic acid on serum and liver lipid levels, urinary excretion of isoprostanes as a biomarker of oxidative stress, expression of aortic monocyte chemoattractant protein-1 (MCP-1) as a biomarker of inflammatory status of endothelial cells (Bursill et al. 2004) and the extent of atherosclerosis in apo E-deficient mice.

\section{Materials and methods}

\section{Animals and diets}

ApoE-deficient mice purchased from Jackson Laboratory (Bar Harbor, ME, USA) in 1994 were used (Ni et al. 1998). Male and female apo E-deficient mice ( 8 weeks old) with an initial weight of 26.4 (SE 0.6) $\mathrm{g}$ for male mice and 22.0 (SE 0.6) $\mathrm{g}$ for female mice were divided into two groups, and were fed an AIN-76 diet 
(Anonymous, 1977) containing saturated and monounsaturated fatty acid-rich fat (SF diet; $50 \mathrm{~g}$ palm oil and $50 \mathrm{~g}$ lard $/ \mathrm{kg}$ ) or HL fat (HL diet; $100 \mathrm{~g}$ high-linoleic safflower-seed oil $/ \mathrm{kg}$ ). The fatty acid composition of the dietary fats is shown in Table 1 . The cholesterol diets were supplemented at the level of $0.4 \mathrm{~g} / \mathrm{kg}$ diet. Safflowerseed oil contained approximately a 10-fold higher amount of $\alpha$-tocopherol compared with the mixed fat composed of palm oil and lard (236 and $24.9 \mathrm{mg} / \mathrm{kg}$ oil for safflower-seed oil and the mixed fat, respectively). Simultaneously, the vitamin mixture of the AIN-76 diet supplies large amounts of $\alpha$-tocopherol, so that the $\alpha$-tocopherol level in the HL diet $(69.1 \mathrm{mg} / \mathrm{kg}$ diet) was approximately 1.5 -fold higher than that in the SF diet $(48.0 \mathrm{mg} / \mathrm{kg}$ diet $)$. The animals were individually housed in a temperature-controlled room at $22-25^{\circ} \mathrm{C}$ with a $12 \mathrm{~h}$ light-dark cycle (lights on, 08.00-20.00 hours). Experimental diets were packaged in a pouch containing an $\mathrm{O}_{2}$ absorbent (Ageless S-200; Mitsubishi Gas Chemical Co., Tokyo, Japan), flushed with $\mathrm{N}_{2}$ and stored at $4^{\circ} \mathrm{C}$. The diet was freshly prepared every week and changed every $2 \mathrm{~d}$ and any remaining diet was discarded. At the end of the 9-week feeding period, the mice were deprived of food for $4 \mathrm{~h}$ before killing. During the week before killing, they were placed in a metabolism cage (Shinano Seisakusho, Tokyo, Japan) where they were freely given the diet and water, and their urine was collected in a container containing butylated hydroxytoluene (final concentration of $453 \mathrm{nmol} / \mathrm{l}$ ) for $24 \mathrm{~h}$ (Tomoyori et al. 2004). The urine was frozen with liquid $\mathrm{N}_{2}$ after blowing Ar through it and then kept at $-85^{\circ} \mathrm{C}$. At the end of the experiment, the mice were anaesthetised by intraperitoneal injection of $50 \mathrm{mg} / \mathrm{kg}$ body weight sodium pentobarbital and killed by withdrawing blood from the left ventricle. The blood was transferred into $1 \mathrm{ml}$ microcentrifuge tubes containing $50 \mu \mathrm{g}$ butylated hydroxytoluene; the serum was then separated, bubbled with $\mathrm{Ar}$ and finally stored at $-85^{\circ} \mathrm{C}$ after being frozen with liquid $\mathrm{N}_{2}$. Livers and aortas were immediately removed from the carcasses, frozen in liquid $\mathrm{N}_{2}$ and stored at $-85^{\circ} \mathrm{C}$. Before freezing, adipose tissue around the aorta was removed, rinsed in fresh PBS and blotted dry between filter paper.

The experiments were carried out following the Guidelines for Animal Experiments at the Faculty of Agriculture and the Graduate Course, Kyushu University, Fukuoka, Japan, and law no. 105 and notification no. 6 of the Government of Japan.

\section{Determination of 8-iso-prostaglandin $F 2 \alpha$}

Purification and measurement of urinary 8 -iso-PGF $2 \alpha$ or 2,3dinor-5,6-dihydro-8-iso-prostaglandin F2 $\alpha$ (15-F2t-IsoP-M) was carried out by combining four methods (Morrow \& Roberts, 1994; Wübert et al. 1997; Schwedhelm et al. 2000; Zhao et al. 2001). 8-Iso-PGF2 $\alpha$ and 15-F2t-IsoP-M were obtained

Table 1. Fatty acid composition of saturated fatty acid-rich fat (SF) and linoleic acid rich-fat $(\mathrm{HL})(\mathrm{g} / 100 \mathrm{~g}$ total fatty acids)

(Mean values with triplicate determination for each group)

\begin{tabular}{lrc}
\hline Fatty acid & SF & HL \\
\hline $14: 0$ & $1 \cdot 4$ & - \\
$16: 0$ & $34 \cdot 4$ & $7 \cdot 0$ \\
$16: 1$ & $2 \cdot 2$ & - \\
$18: 0$ & $9 \cdot 2$ & $2 \cdot 5$ \\
$18: 1$ & $43 \cdot 4$ & $15 \cdot 2$ \\
$18: 2$ & $9 \cdot 8$ & $75 \cdot 4$ \\
\hline
\end{tabular}

from Cayman Chemicals (Ann Arbor, MI, USA). The urine isoprostanes were analysed by GC negative ion chemical ionisation MS; GC negative ion chemical ionisation MS was performed using a Shimadzu QP5050A GC/MS (Shimadzu, Kyoto, Japan). GC was carried out using a $30 \mathrm{~m}, 0.25 \mathrm{~mm}$ diameter, $0.25 \mu \mathrm{m}$ film thick SPB-20 fused silica capillary column (Supelco, Bellefonte, PA, USA). The column temperature was initially maintained at $100^{\circ} \mathrm{C}$ for $2 \mathrm{~min}$, was next heated to $250^{\circ} \mathrm{C}$ in $7 \mathrm{~min}$ and then to $290^{\circ} \mathrm{C}$ at $2^{\circ} \mathrm{C} / \mathrm{min}$ and maintained at this temperature. Isobutane was used as a reactant gas for negative chemical ionisation and the carrier gas used was $\mathrm{He}$ at $1.1 \mathrm{ml} / \mathrm{min}$. The ion source temperature was $290^{\circ} \mathrm{C}$ and the electron energy was $70 \mathrm{eV}$. The ion monitor for endogenous 8-iso-PGF2 $\alpha$ or 15 -F2t-IsoP-M was set at $\mathrm{m} / \mathrm{z}$ 569 (M-181) and $\mathrm{m} / \mathrm{z}$ 547, respectively. 8-Iso-PGF2 $\alpha-\mathrm{d} 4$ (Cayman Chemicals) or 15-F2t-IsoP-M $\left[{ }^{18} \mathrm{O}_{2}\right]$ (kindly donated by $\mathrm{Dr}$ J. D. Morrow, Department of Medicine and Pharmacology, Vanderbilt University, Nashville, TN 37232, USA) was used as an internal standard and ions at $\mathrm{m} / \mathrm{z} 573$ or $\mathrm{m} / \mathrm{z}$ 547 were monitored. The quantification of endogenous 8-isoPGF2 $\alpha$ or $15-F 2 t-I s o P-M$ was accomplished by SIM analysis of the ratio of $\mathrm{m} / \mathrm{z} 569$ to $\mathrm{m} / \mathrm{z} 573$ or $\mathrm{m} / \mathrm{z} 543$ to $\mathrm{m} / \mathrm{z} 547$, where the lower limit of detection (signal:noise ratio of $4: 1$ ) of 8 -isoPGF2 $\alpha$ and 15-F2t-IsoP-M were 28 and 109 pg, respectively. A standard curve was constructed by adding varying amounts of unlabelled 8 -iso-PGF $2 \alpha$ to $1 \mathrm{ng} 8$-isoPGF $2 \alpha$-d 4 or $15-\mathrm{F} 2 \mathrm{t}-\mathrm{IsoP}-\mathrm{M}$ to $1 \mathrm{ng}$ of $15-\mathrm{F} 2 \mathrm{t}-\mathrm{IsoP}-\mathrm{M}\left[{ }^{18} \mathrm{O}_{2}\right]$. The concentration of urine isoprostanes was expressed as a function of urinary creatinine (Wako Pure Chemicals, Osaka, Japan).

\section{Determination of aortic monocyte chemoattractant protein-1 $m R N A$ level by reverse transcription polymerase chain reaction Southern hybridisation analysis}

Total RNA from the mouse aorta was extracted following the method of Chomczynski \& Sacchi (1987). The reverse transcription-PCR was carried out according to the method of Sokolov \& Prockop (1994). Total RNA $(5 \mu \mathrm{g})$ was transcribed into firststrand cDNA using a You-primed cDNA single step kit (Pharmacia Japan, Tokyo, Japan). The primers of mouse MCP-1 were designed according to the data of Kawahara et al. (1991). The sequences were 5'- CACCAGCAAGATGATCCCAATG for the 5'-primer and 5'-AAGGCATCACAGTCCGAGTCACAC for the $3^{\prime}$-primer. Also, the measurement of aortic $\beta$-actin mRNA levels was carried out as a housekeeping gene to confirm stable extraction from these aortic samples. The primer sequences of mouse $\beta$-actin (Shimano et al. 1996) were $5^{\prime}$-GGATCCCAGATCATGTTTGAGACCTTCAA for the $5^{\prime}$-primer and 5'-GAATTCGGAGAGCATAGCCCTCGTAGATGG for the $3^{\prime}$-primer.

PCR amplification of MCP-1 as well as $\beta$-actin was carried out in $10 \mu \mathrm{l}$ reaction mixtures composed of $1 \mu \mathrm{l}$ cDNA solution, 2.5 units of Platinum Taq DNA polymerase (Invitrogen Life Technologies, Carlsbad, CA, USA), $1 \mu 110 \times$ PCR buffer containing $2.5 \mathrm{mM}^{-\mathrm{MgCl}_{2}}$ (attached to the enzyme), $1.6 \mathrm{~mm}$ of each dNTP and 5 pmol each of the two oligonucleotide primers. The amplification conditions were as follows: $95^{\circ} \mathrm{C}, 2 \mathrm{~min} ; 95^{\circ} \mathrm{C}, 1 \mathrm{~min}$, $54^{\circ} \mathrm{C}, 30 \mathrm{~s}, 72^{\circ} \mathrm{C}, 1 \mathrm{~min}$, for forty-two cycles; and finally $72^{\circ} \mathrm{C}$, $5 \mathrm{~min}$. The amplification products obtained using the two primer pairs had $357 \mathrm{bp}$ of MCP-1 or $254 \mathrm{bp}$ of $\beta$-actin. We cloned the PCR products into pGEM-T Easy (Promega, Madison, WI, USA) using a sequence vector to check the sequence with 
a DNA sequencer; Gene Rapid (Amersham Pharmacia Biosciences, Tokyo, Japan).

The aorta total RNA samples from these mice were subjected to RT-PCR as described earlier, but the cycle number was changed from forty-two to twenty cycles for MCP-1 and to sixteen cycles for $\beta$-actin. Southern-blotting hybridisation of the PCR products was carried out as described elsewhere (Wahl et al. 1979). The products on the nitrocellulose filter, Hybond NX (Amersham Pharmacia Biosciences, Tokyo, Japan) were hybridised to ${ }^{32} \mathrm{P}$-labelled probe of the cloned mouse MCP-1 or $\beta$-actin. The exposition intensities of these bands were then quantified by a Bio-imaging analyser FLA-5000 (Fuji Photo Film, Tokyo, Japan). We have confirmed that the concentrations $(0.5$, 1,2 and $3 \mu l$ per $10 \mu l$ reaction solution) of the cDNA from the aorta total RNA were linearly correlated with the radiation activities for MCP-1 $(r$ 0.991; $P<0 \cdot 01)$.

\section{Analyses of serum and liver lipids}

Serum lipid levels were determined using commercially available kits (Cholesterol C test, Triglyceride G Test and Phospholipid B Test from Wako Pure Chemicals, Osaka, Japan and HDL-C.2 from Daiichi Chemicals, Tokyo, Japan) and liver lipids were chemically determined as previously described (Tomoyori et al. 2004). The fatty acid composition of the serum and liver phosphatidylcholine was determined according to methods described previously (Carvajal et al. 2000).

\section{Serum lipid peroxidation}

Lipid peroxidation was quantified by measuring the serum concentration of thiobarbituric acid reactive substances (TBARS) determined to be malonyldialdehyde (MDA), a product of lipid peroxidation as previously described by Yagi (1976).

\section{Serum nitrite plus nitrate}

Serum nitrite plus nitrate $\left(\mathrm{NO}_{2}\right.$ plus $\left.\mathrm{NO}_{3}\right)$ was determined as the final metabolites of NO as described previously (Ni et al. 2003).

\section{Morphometric determination of atherosclerosis}

Apo E-deficient mice were perfused with $50 \mathrm{ml}$ PBS (pH 7.4) via a cannula inserted into the left ventricle, which allowed unrestricted efflux from an incision in the vena cava. After the aorta and its main branches were dissected from the aortic valve to the iliac bifurcation, perfusion of the heart was immediately continued with $50 \mathrm{ml}$ of $10 \%(\mathrm{v} / \mathrm{v})$ neutral formalin buffer solution $(\mathrm{pH} 7 \cdot 4)$. The heart was removed and fixed in $10 \%(\mathrm{v} / \mathrm{v})$ neutral formalin-buffered solution ( $\mathrm{Ni}$ et al. 1998). To determine the cross-sectional lesion area, hearts containing aortic roots were processed for quantitative atherosclerosis assay as previously described (Tomoyori et al. 2004).

\section{Statistics}

The data were expressed as the means with their standard errors and were analysed by two-way ANOVA followed by a post hoc test (Bonferroni-Dunn method). Statistical analysis was carried out with Statcel (OMS, Saitama, Japan) and Excel 2000
(Microsoft, Redmond, WA, USA) and differences were considered to be statistically significant for $P<0.05$.

\section{Results}

There was a difference in the initial mean body weight between females $(21.9$ (SE $(0.6)$ and 22.1 (SE (0.5) g for the SF and HL group, respectively) and males (26.4 (SE (0.7) and 26.4 (SE (0.5) g for the SF and HL group, respectively) $(P<0.01)$. The final mean body weight for the females (32.0 (SE (1.4) and 33.1 (SE (1.5) g for SF and HL group, respectively) was smaller than that for males (41.9 (SE (1.0) and 43.1 (SE (0.8) g for SF and HL group, respectively) $(P<0 \cdot 01)$, but there was no significant dietary fat effect observed. The sex and type of dietary fat had no significant effect on the mean daily food intake: $4 \cdot 2$ (SE $0 \cdot 1$ ) and $4 \cdot 2$ (SE 0.1) g for SF- and LH-fed females, respectively; and 4.8 (SE 0.1) and 4.5 (SE 0.1) g for SF-and HL-fed males, respectively. There was also no significant difference due to sex and type of dietary fat on the relative liver weight (data not shown).

Table 2 shows the degree of atherosclerotic lesions as well as concentrations of the serum and liver lipids, serum $\mathrm{NO}_{2}$ plus $\mathrm{NO}_{3}$, serum TBARS and urinary isoprostanes in the apo E-deficient female and male mice fed a diet containing different fats. Two-way ANOVA revealed main effect of fats on the lesion size in the aortic root $(P<0 \cdot 01)$ and the serum HDL-cholesterol concentrations $(P<0 \cdot 01)$ : the HL diet resulted in a more decreased lesion size and increased HDL-cholesterol concentrations than did the SF diet. There was no main effect of sex on these characteristics. A main effect of the fats was observed on the levels of serum total cholesterol $(P<0.01)$, liver total cholesterol $(P<0 \cdot 01)$ and esterified cholesterol $(P<0.01)$ and the serum TBARS $(P<0 \cdot 01)$. The mice fed the HL diet had a decreased concentration of serum total cholesterol and liver total or esterified cholesterol and increased concentration of serum TBARS compared with the SF-diet mice and these values were higher for males than for females. The atherosclerotic lesion area was significantly negatively correlated to the serum HDL-cholesterol level $(r-0.59 ; P<0.05)$, but was not significantly related to the serum total cholesterol level $(r$ $0.13 ; P>0.1)$. There was no main effect of fats on the concentrations of serum triacylglycerols and $\mathrm{NO}_{2}$ plus $\mathrm{NO}_{3}$. Table 2 also shows the urinary excretion of 8 -iso-PGF $2 \alpha$ or the $\beta$-oxidation product of $15-\mathrm{F} 2 \mathrm{t}-\mathrm{Is}$-P-M. Two-way ANOVA revealed a main effect of fats on the urinary levels of 15-F2t-IsoP-M $(P<0.01)$, but not of 8 -iso-PGF $2 \alpha$. Here, HL diet-fed mice showed increased excretion of the former isoprostane than compared with the SF diet-fed mice and females tended to excrete greater amounts of both isoprostanes. The atherosclerotic lesion area was not significantly related to 8 -iso-PGF2 $\alpha(r-0 \cdot 11$; $P>0 \cdot 1)$ or $15-\mathrm{F} 2 \mathrm{t}-\mathrm{IsoP}-\mathrm{M}(r-0 \cdot 18 ; P>0 \cdot 1)$ in the urine.

Fig. 1 shows MCP-1 mRNA expression over the whole aorta, where aortas that were unbroken from the aortic valve to the iliac bifurcation were used for RNA extraction. Main effects were found for fats on this expression: the HL diet-fed males exhibited increased expression of the mRNA compared with the SF diet-fed males; MCP-1 mRNA expression in females also tended to be lower.

Table 3 shows the fatty acid composition of the serum phosphatidylcholine. There was a prominent difference in the proportion of oleic, linoleic and arachidonic acids between the HL diet-fed and SF diet-fed mice, where a significant sex effect on their 
Table 2. Effect of dietary saturated fatty acid-rich fat (SF) and linoleic acid-rich fat (HL) on atherosclerotic lesions, serum and liver lipids, serum nitric oxides and peroxidation parameters for female and male apolipoprotein E-deficient mice

(Mean values with their standard errors for seven to eight mice per sex for each group)

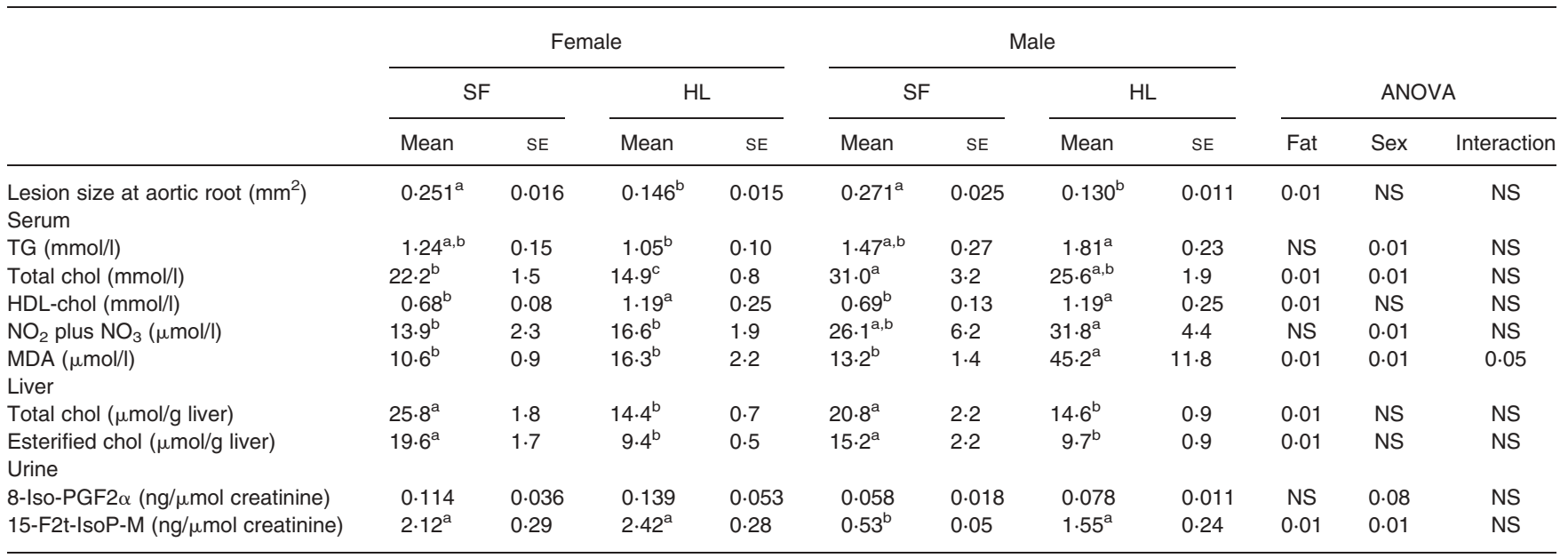

Chol, cholesterol; TG, triacylglycerol; MDA, malondialdehyde; 8-iso-PGF2 $\alpha$, 8-iso-prostaglandin F2 $\alpha$; 15-F2t-IsoP-M, 2,3-dinor-5,6-dihydro-8-iso-prostaglandin F2 $\alpha$.

$a, b, c$ Mean values within a row with unlike superscript letters were significantly different $(P<0.05)$ (Bonferroni-Dunn test).

proportions was seen, but only to a small extent. ANOVA showed a significant diet effect on the proportion of saturated fatty acids (16:0 and 18:0), but the extent was smaller compared with the differences for the unsaturated fatty acids $(18: 1,18: 2$ and $20: 4 n-6)$. For liver phosphatidylcholine, HL diet-fed mice showed an increased proportion of PUFA and a decreased proportion of oleic acid than did the SF group (data not shown).

\section{Discussion}

The novel findings of the present study were the following: (1) atherosclerotic lesion area was greater in the apo E-deficient

(a)

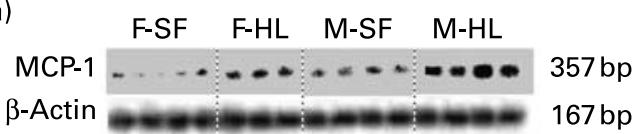

(b)

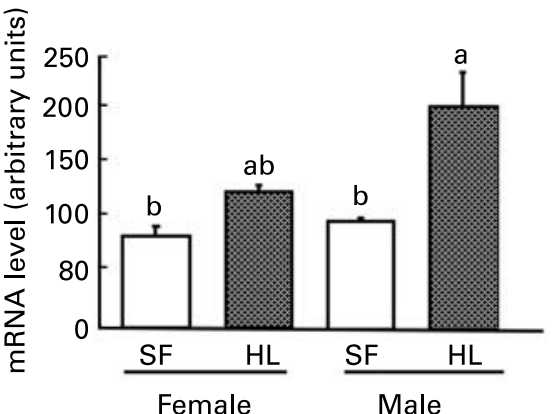

Fig. 1. The effect of dietary saturated fatty acid-rich fat (SF) and linoleic acidrich fat $(\mathrm{HL})$ on aortic mRNA levels of monocyte chemoattractant protein-1 (MCP-1) in apo E-deficient mice. (a) RT-PCR Southern hybridisation analyses for MCP-1 and $\beta$-actin mRNA for each sex and dietary treatment (F-SF, female fed SF diet; F-HL, female fed HL diet; M-SF, male fed SF diet; $\mathrm{M}-\mathrm{HL}$, male fed $\mathrm{HL}$ diet). (b) Mean values for three to five mice per group, with the corresponding standard errors represented by vertical bars. The relative levels of MCP-1 mRNA were normalised to the mean for the aorta from male mice fed an SF diet. ${ }^{a, b}$ Mean values with unlike letters were significantly different $(P<0.05)$. There were significant effects for fat $(P<0.001)$ and for sex $(P<0.005)$, but not for their interaction (ANOVA). mice fed the SF diet than in those fed the HL diet, whereas the extent of biomarkers for oxidative stress (15-F2t-IsoP-M) and inflammatory status (MCP-1 mRNA) in the arterial wall was greater in the latter group than in the former group; (2) the serum total cholesterol level was lower in the HL group than in the SF group, whereas the HDL-cholesterol level was higher in the former group than in the latter group. These results suggest that in apo E-deficient mice, the cholesterol traffic between the serum and arterial wall is the primary determinant for the atherosclerosis process.

In the present study, the HL diet-fed apo E-deficient mice had an increased proportion of linoleic and arachidonic acids in their serum phosphatidylcholine than did the SF diet-fed mice. It is probable that the elevation of these PUFA was associated with increases in serum TBARS and urinary isoprostanes, which are derived from arachidonic acid (Morrow et al. 1999). The results that the HL diet makes serum lipoproteins more susceptible to oxidation are in agreement with those of a previous in vitro study which found an increased rate in conjugate diene formation in LDL enriched with linoleic acid (Reaven et al. 1993), and an in vivo study that found increased urinary excretion of 8 -iso-PGF $2 \alpha$ in human subjects after consumption of a diet rich in linoleic acid compared with an oleic acid-rich diet (Turpeinen et al. 1998). Furthermore, the HL diet compared with the SF diet resulted in increased inflammatory stress as reflected in the increased expression of aortic MCP-1. It is probable that the elevation of MCP-1 mRNA was in part related to increased oxidative stress in mice of the HL group than in those of the SF group, because linoleic and arachidonic acids induce MCP-1 gene expression in cultured cells by activating the oxidative stressresponsive transcription factor NF- $\mathrm{BB}$ (Hennig et al. 1996; Lee et al. 2001).

Despite the above unfavourable effects of the HL diet, the present study found that compared with the apo E-deficient mice fed the SF diet, the HL diet-fed mice had decreased lesion sizes in the aortic root compared with those of the SF group, followed by a decreased serum cholesterol level and an increased level of the serum HDL compared with the SF 
Table 3. Effect of dietary saturated fatty acid-rich fat (SF) and linoleic acid-rich fat (HL) on the fatty acid composition of serum phosphatidylcholine in female and male apolipoprotein E-deficient mice ( $\mathrm{g} / 100 \mathrm{~g}$ total fatty acids)

(Mean values with their standard errors for seven to eight mice per sex for each group)

\begin{tabular}{|c|c|c|c|c|c|c|c|c|c|c|c|}
\hline \multirow[b]{3}{*}{ Fatty acid } & \multicolumn{4}{|c|}{ Female } & \multicolumn{4}{|c|}{ Male } & & & \\
\hline & \multicolumn{2}{|c|}{ SF } & \multicolumn{2}{|c|}{$\mathrm{HL}$} & \multicolumn{2}{|c|}{ SF } & \multicolumn{2}{|c|}{$\mathrm{HL}$} & \multicolumn{3}{|c|}{ ANOVA } \\
\hline & Mean & SE & Mean & $\mathrm{SE}$ & Mean & SE & Mean & SE & Fat & Sex & Interaction \\
\hline $16: 0$ & $27 \cdot 8^{b}$ & 0.4 & $26 \cdot 0^{c}$ & 0.7 & $31 \cdot 3^{a}$ & 0.5 & $28 \cdot 5^{b}$ & 0.4 & 0.01 & 0.01 & NS \\
\hline $16: 1$ & $0.9^{b}$ & 0.2 & $0.7^{\mathrm{b}}$ & 0.2 & $1.9^{a}$ & 0.2 & $0.8^{\mathrm{b}}$ & 0.1 & 0.01 & 0.01 & 0.01 \\
\hline $18: 0$ & $18 \cdot 9^{b}$ & 0.4 & $20 \cdot 1^{d}$ & 0.6 & $13 \cdot 6^{a}$ & 0.2 & $16 \cdot 0^{c}$ & 0.3 & 0.01 & 0.01 & NS \\
\hline $18: 1$ & $18 \cdot 8^{b}$ & 0.4 & $7 \cdot 0^{c}$ & 0.3 & $21 \cdot 3^{a}$ & 0.5 & $7 \cdot 9^{c}$ & 0.3 & 0.01 & 0.01 & 0.05 \\
\hline $18: 2$ & $14 \cdot 7^{\mathrm{a}}$ & 0.5 & $24 \cdot 3^{c}$ & 1.0 & $15 \cdot 5^{\mathrm{a}}$ & 0.8 & $26 \cdot 9^{b}$ & 1.0 & 0.01 & NS & NS \\
\hline $20: 4 n-6$ & $10 \cdot 5^{a}$ & 0.5 & $15 \cdot 1^{b}$ & 0.7 & $9 \cdot 0^{\mathrm{a}}$ & 0.8 & $13 \cdot 4^{b}$ & 0.6 & 0.01 & 0.05 & NS \\
\hline $22: 6 n-3$ & $4 \cdot 1^{b}$ & 0.3 & $3 \cdot 6^{\mathrm{a}, \mathrm{b}}$ & 0.4 & $3 \cdot 3^{a}$ & 0.2 & $3 \cdot 0^{\mathrm{a}}$ & 0.2 & NS & 0.05 & NS \\
\hline
\end{tabular}

a,b,c Mean values within a row with unlike superscript letters were significantly different $(P<0.05)$ (Bonferroni-Dunn test).

diet group. These favourable effects of the HL diet have also been observed in studies on the African green monkey (Rudel et al. 1995), LDL receptor-deficient human apo B-transgenic mice (Rudel et al. 1998), and LDL receptor-deficient mice (George et al. 2000). In these experiments, the SF diet contained palm oil (49\% palmitic acid and $37 \%$ oleic acid; Rudel et al. 1995, 1998) or cocoa butter (43\% palmitic plus stearic acid and $35 \%$ oleic acid; George et al. 2000) as the primary source of dietary fat. Therefore, the diets designated SF diets in the present and previous studies (Rudel et al. 1995, 1998; George et al. 2000) contained almost equal proportions of saturated fatty acids and MUFA. Hence, it may not be appropriate to term them SF diets. In addition, Calleja et al. (1999) reported that male apo E-deficient mice fed a chowbased diet containing $10 \%$ sunflower-seed oil $(56 \%$ linoleic acid) had fewer lesions than did those fed $10 \%$ palm oil. In contrast, Merkel et al. (2001) reported that there were no significant differences in the atherosclerotic lesion areas between HL diet-fed LDL receptor-deficient mice and SF diet-fed LDL receptor-deficient mice, and between HL diet-fed apo Edeficient mice and SF diet-fed apo E-deficient mice. In their experiments they (Merkel et al. 2001) used coconut oil (71\% saturated fatty acids and 19\% MUFA) as a primary source of dietary fats for the SF diet. For the same experiments with the LDL receptor-deficient mice, compared with the SF and HL diets, the MUFA-rich diet (oleic acid-enriched safflowerseed oil as primary fat; $71 \%$ MUFA) significantly increased atherosclerosis in both sexes (Merkel et al. 2001). As described earlier, Rudel and colleagues (Rudel et al. 1995, 1998) used two animal models to compare the effect of various dietary fats on atherosclerosis. Animals fed an SF diet (palm oil as the primary fat source; $49 \%$ palmitic acid and $37 \%$ oleic acid) and a MUFA-rich diet (oleic acid-enriched safflowerseed oil as the primary fat source; 71\% MUFA) developed equivalent numbers of atherosclerotic lesions and those fed the HL diet developed fewer. From these results, it is probable that dietary enrichment of linoleic acid is associated with a reduction in the extent of atherosclerotic lesion development in the atherosclerosis-susceptible mice model. Furthermore, dietary fats rich in saturated fatty acids and MUFA rather than dietary fats enriched in saturated fatty acid alone appear to be more atherogenic than did linoleic acid-rich diets.

Although the present study was not designed to explore the mechanism whereby an HL diet positively prevents atherosclerosis susceptibility, the opposing results for the atherosclerotic lesion area and the MCP-1 mRNA expression between apo E-deficient mice fed the HL diet and SF diet suggests that dietary factors could be involved in influencing monocyte chemoattraction to arterial intima. Several animal studies found a role for the CC-chemokine receptor 2 in atherosclerosis (Boring et al. 1998; Guo et al. 2003). CC-chemokine receptor 2 is expressed on circulating monocytes, and this expression is up regulated in hypercholesterolaemia and suppressed by elevated levels of HDL (Han et al. 1999). In the present study, the HL diet resulted in lower serum cholesterol and elevated HDL-cholesterol levels. Therefore, it remains to be determined if an HL diet is involved in lowering the recruitment of circulating monocytes into the arterial intima by reducing the expression of CC-chemokine receptor 2.

In summary, the present study found that an HL diet in vivo induces oxidative and inflammatory stresses as an adverse effect but improves serum lipoprotein cholesterol levels as a beneficial effect, and their net effect is an anti-atherogenic state in apo E-deficient mice. Therefore, having biomarkers in vivo for oxidative stress and inflammatory status of endothelial cells does not necessarily show a predisposition toward atherosclerosis initiation or development in this animal model when fed different dietary fats.

\section{Acknowledgements}

This research was supported in part by a Grant-in-Aid for Scientific Research (B) (2) (11460060 and 16380090). 15-F2t-IsoP$\mathrm{M}\left[{ }^{18} \mathrm{O}_{2}\right]$ was kindly donated by Dr J. D. Morrow (Department of Medicine and Pharmacology, Vanderbilt University, Nashville, TN 37232 , USA).

\section{References}

Anonymous (1977) Report of the American Institute of Nutrition Ad Hoc Committee on Standard for Nutritional Studies. J Nutr 107, $1340-1348$.

Bonetti PO, Lerman LO \& Lerman A (2003) Endothelial dysfunction: a marker of atherosclerotic risk. Arterioscler Thromb Vasc Biol 23, $168-175$.

Boring L, Gosling J, Cleary M \& Charo IF (1998) Decreased lesion formation in CCR2 - /- mice reveals a role for chemokines in the initiation of atherosclerosis. Nature 394, 894-897. 
Bursill CA, Channon KM \& Greaves DR (2004) The role of chemokines in atherosclerosis: recent evidence from experimental models and population genetics. Cur Opin Lipidol 15, 145-149.

Calleja L, París MA, Paul A, Vilella E, Joven J, Jimênez A, Beltrán G, Uceda M, Maeda N \& Osada J (1999) Low-cholesterol and high-fat diets reduces atherosclerotic lesion development in apo E-knockout mice. Arteriol Thromb Vas Biol 19, 2368-2375.

Carvajal O, Nakayama M, Kishi T, Sato M, Ikeda I \& Imaizumi K (2000) Effect of medium-chain fatty acid positional distribution in dietary triacylglycerol on lymphatic lipid transport and chylomicron composition in rats. Lipids 35, 1345-1351.

Chomczynski P \& Sacchi N (1987) Single-step method of RNA isolation by acid guanidium thiocyanate-phenol-chloroform extraction. Anal Biochem 162, 156-159.

George J, Mulkins M, Casey S, Schatzmaan R, Sigal E \& Harats D (2000) The effect of $n-6$ polyunsaturated fatty acid supplementation on the lipid composition and atherogenesis in mouse models of atherosclerosis. Atherosclerosis 150, 285-293.

Guo J, van Eck M, Twisk J, Maeda N, Benson GM, Groot PHE \& van Berkel TJC (2003) Transplantation of monocyte CC-chemokine receptor 2-deficient bone marrow into ApoE3-Leiden mice inhibits atherogenesis. Arterioscler Thromb Vasc Biol 23, 447-453.

Han KH, Han KO, Green SR \& Quehenberger O (1999) Expression of the monocyte chemoattractant protein-1 receptor CCR2 is increased in hypercholesterolemia. Differential effects of plasma lipoproteins on monocyte function. J Lipid Res 40, 1053-1063.

Hennig B, Toborek M, Joshi-Barve S, Barger SW, Barve S, Mattson MP \& McClain CJ (1996) Linoleic acid activates nuclear transcription factor-kappa B (NF-kappa B) and induces NF-kappa B-dependent transcription in cultured endothelial cells. Am J Clin Nutr 63, 322-328.

Kawahara RS, Deng ZW \& Deuel TF (1991) Glucocorticoids inhibit the transcriptional induction of JE, a platelet-derived growth factor-inducible gene. J Biol Chem 266, 13261-13266.

Krauss RM, Eckel RH, Howard B, et al. (2000) AHA Dietary Guidelines: revision 2000: a statement for healthcare professionals from the Nutrition Committee of the American Heart Association. Circulation 102, 2284-2299.

Lee YW, Park HJ, Henning B \& Toborek M (2001) Linoleic acid induces MCP-1 gene expression in human microvascular endothelial cells through an oxidative mechanism. J Nutr Biochem 12, 648-654.

Merkel M, Velez-Carrasco W, Hudgins LC \& Breslow JL (2001) Compared with saturated fatty acids, dietary monounsaturated fatty acids and carbohydrates increases atherosclerosis and VLDL cholesterol levels in LDL receptor-deficient, but not apolipoprotein E-deficient, mice. Proc Natl Acad Sci USA 98, 13294-13299.

Mertens A \& Holvoet P (2001) Oxidized LDL and HDL: antagonists in atherothrombosis. FASEB $J \mathbf{1 5}, 2073-2084$.

Moreno JJ \& Mitjavila MT (2003) The degree of unsaturation of dietary fatty acids and the development of atherosclerosis. J Nutr Biochem 14, 182-195.

Morrow JD, Chen Y, Brame CJ, Yang J, Sanchez SC, Xu J, Zackert WE \& Roberts LJ (1999) The isoprostanes: unique prostaglandin-like products of free-radical-initiated lipid peroxidation. Drug Metabol Rev 31, $117-139$.

Morrow JD, Frei B, Longmire AW, Gaziano JM, Lynch SM, Shyr Y, Strauss WE, Oates JA \& Roberts LJ (1995) Increase in circulating products of lipid peroxidation (F2-isoprostanes) in smokers. Smoking as a cause of oxidative damage. $N$ Engl J Med 332, 1198-1203.
Morrow JD \& Roberts LJ (1994) Mass spectrometry of prostanoids: F2isoprostanes produced by non-cyclooxygenase free radical-catalyzed mechanism. Methods Enzymol 233, 163-174.

Napoli C, de Nigris F \& Palinski W (2001) Multiple role of reactive oxygen species in the arterial wall. J Cell Biochem 82, 674-682.

Ni W, Tsuda Y, Sakono M \& Imaizumi K (1998) Dietary soy protein isolate, compared with casein, reduces atherosclerotic lesion area in apolipoprotein E-deficient mice. $J$ Nutr 128, 1884-1889.

Ni W, Tsuda Y, Takashima T, Sato H, Sato M \& Imaizumi K (2003) Antiatherogenic effect of soya and rice-protein isolate, compared with casein, in apolipoprotein E-deficient mice. Br J Nutr 90, 13-20.

Reaven P, Parthasarathy S, Grasse BJ, Miller E, Steinberg D \& Witztum JL (1993) Effects of oleate-rich and linoleate-rich diets on the susceptibility of low density lipoprotein to oxidative modification in mildly hypercholesterolemic subjects. $J$ Clin Invest 91, 668-676.

Rudel LL, Kelley K, Sawyer JK, Shah R \& Wilson MD (1998) Dietary monounsaturated fatty acids promote aortic atherosclerosis in LDL receptor-null, human apo B100-overexpressing transgenic mice. Arterioscler Thromb Vasc Biol 18, 1818-1827.

Rudel LL, Parks JS \& Sawyer JK (1995) Compared with dietary monounsaturated and saturated fat, polyunsaturated fat protects African green monkeys from coronary artery atherosclerosis. Arterioscler Thromb Vasc Biol 15, 2101-2110.

Schwedhelm E, Tsikas D, Durand T, Gutzki FM, Guy A, Rossi JC \& Frölich JC (2000) Tandem mass spectrometric quantification of 8-isoprostaglandin F2 $\alpha$ and its metabolite 2,3-dinor-5,6-dihydro-8-iso-prostaglandin F2 $\alpha$ in human urine. J Chromatogr 744B 99-112.

Shimano H, Horton JD, Hammer RE, Shimomura I, Brown MS \& Goldstein JL (1996) Overproduction of cholesterol and fatty acids causes massive liver enlargement in transgenic mice expressing truncated SREBP-1a. J Clin Invest 98, 1575-1584.

Sokolov BP \& Prockop DJ (1994) A rapid and simple PCR-based method for isolation of cDNAs from differentially expressed genes. Nucleic Acids Res 22, 4009-4015.

Tomoyori H, Kawata Y, Higuchi T, Ichi I, Sato H, Sato M, Ikeda I \& Imaizumi K (2004) Phytosterol oxidation products are absorbed in the intestinal lymphatics in rats but do not accelerate atherosclerosis in apolipoprotein E-deficient mice. $J$ Nutr 134, 1690-1696.

Turpeinen AM, Basu S \& Mutanen M (1998) A high linoleic acid diet increases oxidative stress in vivo and affects nitric oxide metabolism in humans. Prostaglandins Leukot Essent Fatty Acids 59, 229-233.

Vogel RA (1999) Cholesterol lowering and endothelial function. Am J Med 107, 479-487.

Wahl GM, Stern M \& Stark GR (1979) Efficient transfer of large DNA fragments from agarose gels to diazobenzyloxymethyl-paper and rapid hybridization by using dextran sulfate. Proc Natl Acad Sci USA 76, 3683-3687.

Wübert J, Reder E, Kaser A, Weber PC \& Lorenz RL (1997) Simultaneous solid phase extraction, derivatization, and gas chromatographic mass spectrometric quantification of thromboxane and prostacyclin metabolites, prostaglandins, and isoprostanes in urine. Anal Chem 69, 2143-2146.

Yagi K (1976) A simple fluorometric assay for lipoprotein in blood plasma. Biochem Med 15, 212-216.

Zhao Z, Hjelm NM, Lam CWK \& Ho C (2001) One-step solid-phase extraction procedure for F(2)-isoprostanes. Clin Chem 47, 1306-1308. 